\title{
The Inexact Science of Informing Ourselves
}

\author{
Lynne Marie Rudasill \\ University of Illinois at \\ Urbana Champaign, Urbana, \\ IL, USA
}

\author{
Katherine McNeill- \\ Harman \\ Massachusetts Institute of \\ Technology, Cambridge, \\ MA, USA
}

rudasill@uiuc.edu mcnellih@mit.edu

acobs@uiuc.edu

\begin{abstract}
Advances in information technology provide opportunities to inform users in ways that were only imagined twenty years ago. However, information providers need to inform themselves concerning the best way to deliver resources to these users. Often assumptions are made about users that are inaccurate and untrue. With a view to these shortcomings, a team came together to collect information from users to assist in the redevelopment of a departmental library homepage at a major U.S. university. Methods used by social science researchers and by businesses to ascertain customer preferences were employed to increase understanding of the needs and desires of library users. Applying the tools of qualitative research improved understanding of the inexact science one must practice in dealing with diverse groups. This paper is a report of the findings, some surprising, some expected, but all relevant to the shape "Informing Science" takes in one library.
\end{abstract}

Keywords: Libraries, Focus Groups, Usability, Web page design, User-centered design

\section{Introduction}

This paper outlines the process by which University of Illinois Education and Social Science Library (ESSL) staff investigated and incorporated user needs and feedback into the redesign of the departmental library's home page. What do users really want from library web access? How can users' desires and the need to provide access to a large, often confusing, body of information be combined in the provision of electronic access? What is the best way to obtain user feedback in a systematic manner concerning the problems of electronic access? Having received input from other librarians, the researchers felt it important to gain direct feedback from users in order to design a page that would best meet the user needs. Various methods were employed to gain this information: focus groups, usability testing, and a survey. This paper discusses how the results were utilized to develop a more helpful web page

The information access possibilities of the World Wide Web are immense, providing information-seeking individuals powerful tools with which to fulfill their needs. Nowhere is this access more apparent than in the university research library. The University Library at the University of Illinois at Urbana-Champaign

Material published as part of these proceedings, either on-line or in print, is copyrighted by Informing Science. Permission to make digital or paper copy of part or all of these works for personal or classroom use is granted without fee provided that the copies are not made or distributed for profit or commercial advantage AND that copies 1) bear this notice in full and 2) give the full citation on the first page. It is permissible to abstract these works so long as credit is given. To copy in all other cases or to republish or to post on a server or to redistribute to lists requires specific permission from the publisher at Publister@intommingscience.org has holdings of approximately nine and one-half million volumes in traditional format, and thousands of electronic databases, electronic journals, and other full-text resources. These resources exist within a decentralized system of over forty unit and departmental libraries. Providing easy access to these tools for 36,000 students and over 2,000 faculty members is imperative if the large cost of subscriptions is to be justified. In 1994, the first 
graphical web page for a campus library at the University was created for Grainger Engineering Library at the University of Illinois (Cole, 1995). This first page was quickly followed by pages for other units in the University Library. A variety of formats for home pages were developed based primarily upon the perceptions of the unit and departmental librarians regarding needs and wants of the library user and the desire to provide easy access to the many resources available. In 1996, a committee at the University Library began work to mount a navigation bar on its web site that would allow users uniform access to a variety of materials: the online catalog; electronic indexes and abstracts; information about the library, its units, their locations, and hours; and assistance in learning to use the library. In addition to a presence on the University Library home page, the Library Gateway navigation bar, providing uniform access to these resources, could be found on the left-hand side of all unit and departmental home pages.

ESSL is one of the many departmental libraries. Materials held within this location focus on the disciplines of anthropology, education, political science, psychology, social work, sociology, and speech communication. In addition, the unit houses several special collections and is responsible for collecting in the general areas of the social sciences and social science statistics. ESSL is one of the busiest libraries in the University Library system, answering about 30,000 reference questions per year. It developed a web presence at the earliest opportunity. The original page listed the resources available electronically under several general categories (Appendix A). When the Gateway came into production, the page was slightly reconfigured to accommodate the needed space (Appendix B). In the years following, hyperlinks to new items were gradually added to the page under the original categories. By the spring of 2001, the page was extensive, resulting in the need to scroll through several pages to find desired resources.

In late 2000, the University Library appointed a task force to redesign the Gateway. Redesign was necessary to address changing user needs, take advantage of new technology, and provide a more uniform look for the Library's web pages. At that time, the librarians at ESSL thought it opportune to revise its web page. Taking a cue from the Gateway redesign project, which had employed usability testing to aid in the redevelopment of its web pages, the department decided to obtain as much user input as possible in the development of its new page. A grant was received from the Library Research and Publication Committee to supplement the resources of ESSL. A three-member team was put together consisting of one librarian from the department and two graduate students from the Graduate School of Library and Information Science. Two of the members had been working with the Library Gateway redesign task force and were familiar with the issues and challenges in need of being addressed. In addition, members of the team had experience with focus groups, usability testing, and the technical skills required for developing web pages. In spring of 2001, the project was begun.

\section{The Literature of Redevelopment}

A review of the literature pertaining to interface design and evaluation methods was the first step taken. Material was identified in the fields of user interface design, human-computer interaction (HCI), social science research methods, and user studies. Literature was found pertaining to those methods under consideration: usability testing, focus groups, and surveys. Studies from academic, corporate, and library settings provided insight on both theoretical issues and the application of research methods.

Several important works discuss the process of designing and evaluating computer interfaces. Mayhew (1999) describes the full process of user interface design as including design, testing, development, and user feedback. Ben Shneiderman, a prominent researcher in the field of human-computer interaction, has been writing about user interface design since the 1980s (1987, 1992). Material in his most recent work is helpful to researchers and practitioners in a wide range of fields. It reviews theories of HCI, the development and evaluation of interfaces, and the implications of new technology upon design (Shneiderman, 1998). 
Another major researcher in the field of interface design, focusing largely on web usability, is Jakob Nielsen, whose work the group relied upon in developing this study. His work on the heuristics of web design provides standards for creating usable sites (Nielsen, 2000). Nielsen was also consulted for advice on the application of usability testing. His research concludes that most of what is learned in the process can be discovered in the study of as few as five individuals (Nielsen, 2001). Moreover, Nielsen has authored two important books on usability. The first provides a general overview of usability theories regarding computer systems in general and discusses usability testing methods (Nielsen, 1994). In his more recent work, the author focuses specifically on these issues as they relate to web sites (Nielsen, 2000).

Several additional works provide practical guidance on the implementation of usability testing. Lindgaard (1994) outlines how to collect data and the techniques of usability testing. In addition, Ruben (1994) has written an excellent handbook that provides a step-by-step process regarding the design and application of usability testing. Norlin (2002) documents this method within the specific context of the library web site, particularly applicable to our research. Allen (1996), Bawden (1990), and Wood (1998) have each authored other useful works to consult on user interface design.

Several articles provide examples of usability testing in academic library settings. Walbridge's article on Washington State University outlines fundamental methods of testing, including establishing a test research question, recruiting test subjects, obtaining the appropriate facility and equipment, encouraging participants to think out loud, post-session debriefing, and rapid analysis of the results (Walbridge, 2000). Three recent articles that reported on representative case studies in the area of usability testing in the academic library are also very helpful. Reports on the use of the process at Roger Williams University, the University of South Florida, the University at Buffalo, and the Memorial University of Newfoundland provide information on usability testing of the structure and performance of library web sites (McMullen, 2001; Battleson, Booth, \& Weintrop, 2001; and McGillis \& Toms, 2001).

Literature from a variety of sources was used to investigate the process involved in running focus groups. An early article by Young (1993) provides an excellent basic guide to the process, discussing the rationale for focus groups, a step-by-step process for the successful completion of a group session, and some cautions about findings. A later work by Connaway (1996) reiterated the admonition of Young that results from one session could not be generalized to an entire population. Indeed, "the results give one the opportunity to consider a range of responses" (p. 235). This information was instrumental in the decision to run focus groups for each of three populations: faculty, graduate students and undergraduate students. Although this goal was not achieved--an appropriate number of undergraduates could not be found to participate--researchers worked to conduct a thorough examination of the library's population of users. In additional literature, an article by Nielsen (1997) entitled "The Use and Misuse of Focus Groups" clearly identifies aspects of focus group work of which one should be aware. Glitz (1997) provides further background in the use of focus groups in libraries, discussing their role in qualitative research.

In addition, several excellent books are recommended in the preparation for focus group administration. The first, Focus Group Research Handbook, provides comprehensive coverage of the topic, from items to consider in choosing a facility to the ethics of focus group research (Edmunds, 1999). The information found in this work of most importance to the team revolved around the choice of a moderator for the discussions. While using an outside consultant as facilitator would have provided the greatest level of objectivity, the research budget could not accommodate this cost; thus, the groups had to be facilitated by a member of the team. A second work provided an institutionally grounded guide to the focus group in our particular setting (Glitz, 1998). The book provides advice for moderators and suggestions for other applications of focus groups for libraries. Finally, the work entitled Advanced Focus Group Research provided information beyond the basics in discussing the conceptual framework of focus groups and offered suggestions for the compilation of results (Fern, 2001). 
In addition to the aforementioned literature on specific methodology, social scientists and researchers in the field of library and information science provided guidance in the proposed research. Handbooks on social science research methodology were helpful in preparing for a variety of methods (Bickman \& Rog, 1998; Silverman, 2000). In the field of library and information science, theorists such as Schlichter and Pemberton (1992) urge researchers to focus user studies on specific services or issues, rather than general satisfaction with the library, and to listen closely to their patrons during the planning process. Researchers at the University of Arizona Library learned the importance of the latter while conducting a recent web redesign. While most librarians desired an access page for indexes that contained twelve subject headings, the group had to respond to users' requests for as many as thirty-seven possible subject headings (Dickstein and Mills, 2000).

These practical studies in library settings, as well as the literature in the range of areas consulted, informed our choice and use of methodology to study the needs of our users with respect to a redesign of our web site.

\section{Methodology}

The initial task was to identify the problems with the page. The apparent problems to those undertaking the study were:

- The page was too long. A great deal of scrolling was necessary to access all of its options.

- The text was too dense, with virtually all of the options on the top level of the web site.

- The structure did not take full advantage of the possibilities of hypertext such as the ability to repeat options.

- It was not visually exciting.

Four areas were identified for improvement. First, the page had to be made less cluttered while continuing to provide direct links to a variety of resources. Second, subject area resource guides needed to be more robust, and a template needed to be created for uniformity in resource presentation. Third, the page needed to be moved from a resource-based model to a user-based model. Finally, and perhaps most importantly, the page needed to be made more efficient for the experienced user and more intuitive for the novice user.

The decision was made to do a thorough reassessment of the usefulness of the information presented on the page and, if needed, to make radical changes. The information necessary to make this happen would be obtained through several steps. First, a card sort of the options on the page would be done to discover new ways in which a menu might be organized. Second, prototype pages would be developed for presentation to users. Third, focus groups would be used to assess the general reaction to the new designs.

Fourth, usability testing would be necessary to determine whether or not the changes were effective and the resulting page was more intuitive for the users of the Library when trying to complete typical research tasks. Finally, a survey of on-site users would complete the compilation of information on the user's reaction to the new design.

\section{Card Sort}

Card sorting is a technique for organizing items on a web site into categories. Each item or link is written on a card and the participants organize them into the categories that make the most sense to them. According to Faiks and Hyland, "Card sorting works well in the early stages [of web design] because it gives users an opportunity to create a proposed organization as opposed to reacting to one already in place (2000)." Time constraints prevented the use of patrons of the library in doing a card sort therefore sorting 
was done by the project team. Terms for available resources were identified and copied from the web page onto individual cards. Cards were organized in alphabetical order to minimize bias toward the organizational scheme in use on the page. Team members were instructed to sort the cards into categories and set aside those that should not be on the main page. Blank cards of the same color were to be used to add links that were not available in the current iteration. The cards that were retained could be re-labeled in an alternative manner if necessary. Cards were grouped in the manner that made most sense to each team member. Finally, members assigned headings or names for the groupings. Selections from this process would form the basis for the redesign. After the three team members completed this process, results were compared and suggestions made for appropriate groupings.

The results supported the move from a resource-based model for the page design to one that would be more user-focused based upon types or disciplines of research, with subject guides for the novice and quick links for the experienced users. In addition, some general links would lead to information about the library and its services, while another set of links would provide access to selected resources of a specific research nature. The redundancy of resource links provided by hypertext was seen as an advantage, as users would come to the page from a variety of angles.

\section{Technical Issues}

After the terms to be placed on the page were chosen, two prototype pages were developed, as well as an enhanced version of the existing page with highlighted categories. Several constraints were acknowledged in the development of the new page. It would not be possible to use proprietary design software such as Flash, as it would seriously slow the load-time for the page and might require users to download unwanted software onto their machines. Moreover, many of our users access the site with POT (Plain Old Telephone) technology and any exciting effects might be lost in the transfer. For these reasons, complex images were to be avoided on the page. It was also decided that frames would be inappropriate. The design needed to save room for the Gateway navigation bar on the left side of the screen. In addition, frames do not work well for users with text browsers and many browser readers. The page would have to be compliant with regulations regarding accessibility to users with disabilities. Ultimately, the overriding technical issues involved speed and space. How could the page provide the massive amount of information available to the University community quickly and easily, and stay within usability- and Library-wide style guidelines?

A number of sites were searched for ideas. Both academic and commercial sites were explored to survey the design possibilities. Sites involving scrolling, drop-down lists, and image-maps were viewed. Many appealing sites used Java or were graphically intensive, yet several good examples of the drop-down list were found and assessed. It was decided this would be the best way to present the large number of resources available in a compact manner.

In addition to designing an enhanced version of the page in use at the time (Appendix C), members designed two prototypes. As a beginning, all links to resources were reorganized under six main headings: Quick Connections, Catalogs, Subject Areas, Special Collections, Electronic Resources, and Library Services. A paragraph under the heading banner briefly described how to use the drop-down lists. In Prototype A, a brief explanation of each category was written describing the contents of the drop-down list (Appendix D). In Prototype B, categories remained the same, but the most frequently used links were brought to the main page for one-click access (Appendix E). These "hot links" were chosen on the basis of user observation by individuals working at the reference desk. In both prototypes the drop-down lists were the complete collection of links for each grouping presented in alphabetical order. The select and click method was chosen to accommodate users with disabilities and those who would be working with older or non-graphical interfaces. 
"Subject Areas" led to an alphabetical list of the disciplines found in ESSL, each linked to a related resource page. An online guide describing the reference collection in each subject area had always been available, but hidden quite a distance down on the main page. The subject guides were moved up in order to make them much more apparent. In addition, the second-level subject related pages were standardized and updated to include contact information for the subject specialist librarian and links to suggested electronic abstracts and indexes, the related teaching department, web resources, electronic journals in the discipline, and any special collections related to the subject.

The designer was well versed in HTML and Web site design, using Notetab Lite as the HTML editing tool. The use of an Active Server Page (ASP) infrastructure on the library Web site necessitated a working knowledge of ASP. Sams Teach Yourself ASP 3.0 in 21 Days (Mitchell and Atkinson, 2000) and the assistance of the Library Systems Office provided the necessary assistance in this area. The enhanced original page plus two new offerings then were ready to be viewed by an audience.

\section{Focus Groups}

A great deal of literature had been read concerning the focus group process. Ideally, groups consist of eight to ten members moderated by a consultant familiar with the materials being discussed. As mentioned earlier, one of the team members was chosen to moderate the discussion due to budgetary concerns. While the moderator would know the subject area, care had to be taken to avoid leading the conversation.

Groups were then organized to discuss their preferences on the various pages proposed. Faculty members of the departments covered by ESSL were contacted via e-mail. Volunteers were promised lunch and a gift certificate to a local bookstore. Faculty members from the departments of anthropology, political science, psychology, and speech communication, as well as the administrative assistant from the sociology department took part in the discussions. Participants were forwarded the URLs by which they could access the various iterations of the proposed re-design. They were asked to look at all three versions of the page in order to share their perceptions of the proposed pages. A script was developed to guide the discussion.

Discussions with faculty were fruitful. Several members expressed concern that the original ESSL home page might prove unfriendly to users. The phrase "it's too busy" was used repeatedly to describe the page. The group liked the idea of drop-down menus under the various categories offered. There was some confusion as to where the drop-down menus would lead in Prototype A. Focus group members preferred quick links to resources as opposed to an explanation of each category. The quick link access was more apparent in Prototype B. The session was extremely useful in ways other than those expected. To the team's dismay, it was discovered that many of the faculty members had never used the unit's home page to access resources. Several simply book-marked the items they used most frequently. One faculty member admitted to not even knowing the individual departments had home pages. In addition, it was difficult to keep the faculty members focused on what they wanted in the way of access. Several initiated discussions concerning what the undergraduate student might require in the way of electronic support.

The assumption by the librarians in the unit had been that faculty would be using this page for two purposes: first, to stay aware of the services provided by the unit, and second, to obtain quick access to a variety of materials for their own research. This was conveyed to the faculty focus group. The concern about undergraduate use of the site was alleviated when it was emphasized that both graduate and undergraduate focus groups were planned for the future. Two features related specifically to faculty needs surfaced. First, the group wanted easy access to the interlibrary loan features of the library, and second, access to information about placing requests for class reserves was important to them. 
The second focus group consisted of graduate students from most departments affiliated with ESSL. Messages had been sent to the list of graduate students in each of the areas served with the same information given to the faculty members. Opinions were mixed regarding the enhanced version of the existing page. Although most agreed it was too busy, some indicated an appreciation for the fact that all resources could be viewed. Many of the suggestions that were made were unique and imaginative, but not executable at this time. One participant suggested having separate pages for experienced and novice users. Another suggested a description of each menu item that would appear when one "rolled-over" the name of the resource with the mouse. Someone else suggested a "dialog-based" interface that would ask users who they were and what they were looking for and would then provide access to a list of appropriate resources. As an alternative to this, another participant suggested that the subject area guides could be used as "portals" to specific areas.

A distinct split was readily apparent in the preferences of this group. By a slight margin this group preferred Prototype B, the page with direct links, and made several suggestions for changes that were eventually made to the page. However, a sizeable minority preferred Prototype A. In addition to enhancing the subject access, participants made suggestions regarding the ordering of the categories on the page, including moving "Special Collections" further down on the page and moving "Library Services" and "Electronic Resources" to a place higher on the page. They also suggested a larger font for the quick links being offered. Many in this group were teaching assistants and their experience in dealing with undergraduate students was quite apparent in their suggestions for the novice user. The concern displayed by both the faculty and graduate students for the undergraduate user provided the team with some good information. This was helpful since the third focus group, intended for undergraduate students, did not materialize. The study conducted during the summer session when fewer undergraduates were on campus.

\section{Usability Testing}

To prepare for this phase of the project test scripts were developed for graduate and undergraduate students. Questions on the scripts related to specific tasks required in defined topical areas as well as general library information. A pool of three candidates was chosen from the volunteers answering a call put out on the home page. Participants were given a total of seventeen tasks to complete related to finding subject resources, hours, phone numbers, access to the online catalog, and information contained in special collections. Sessions were recorded on audiotape. In addition a software program capable of recording mouse movements in real time was used to capture the process. The test administrator described the tasks while the other team members took notes. In each session, the administrator emphasized to the participant the importance of thinking aloud. It was also important the participant understand that the page, not his or her skill, was being tested. After the test, the participant was asked to complete a post-test questionnaire.

Several layout problems became apparent during this process. First, the explanatory paragraph under the banner was seen as redundant and, therefore, eliminated. Second, a table was created directly under the banner listing the individual subject areas, as well as access points for library hours and contact information. The labels for the categories were changed slightly and reordered. Text was added as the first line in each of the drop-down lists to read "Click here to browse more options". Items offered as direct links were repeated in these lists. The page went into use during the first week of classes in the fall semester of 2001.

\section{Survey}

The final step in reconfiguration of the page was to survey users. The decision was made to create a traditional paper survey rather than a web-based survey. The instrument consisted of six closed-ended questions on the front of the page and three open-ended questions on the back. Questions on the first page were based on a Likert scale offering the responses, "strongly agree, agree, neutral, disagree, and strongly 
Inexact Science of Informing Ourselves

disagree." The questions related to the ease of finding hours, finding information about subject areas, contacting a librarian working in the subject area, use of the drop-down lists, general navigation on the page, and the appropriateness of the categories that were displayed. The surveys were distributed to library patrons working at public access terminals in ESSL.

The results of the forty-seven completed surveys are shown in Table 1 below. The generally positive responses to the redesign were encouraging to the team.

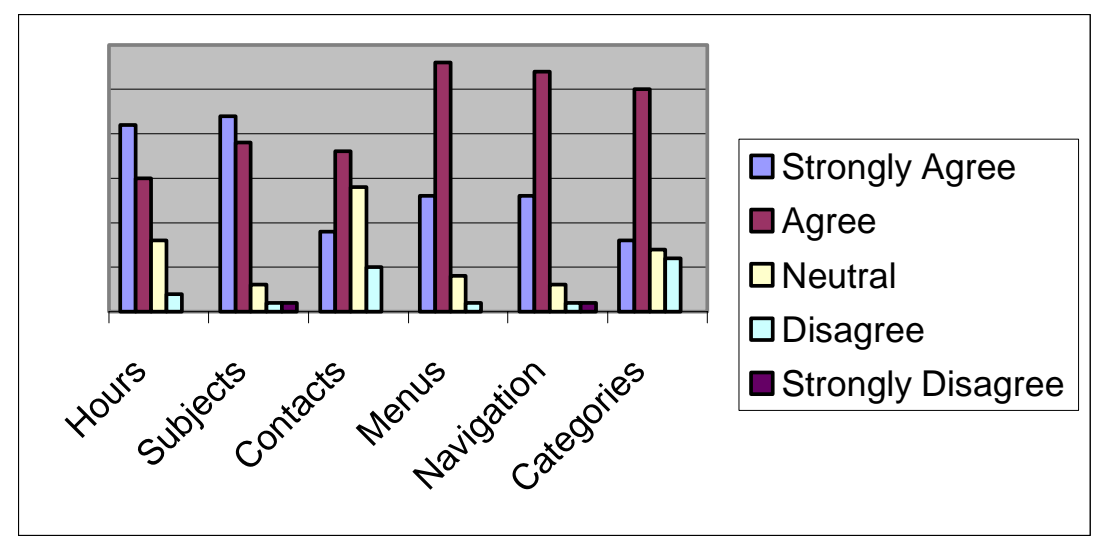

Table 1. Survey Results

The textual comments on the second page were also positive. Respondents were asked to provide statements concerning the one thing they would change on the new page, one thing they liked best about the new page, and the most difficult part of the page to understand. Patrons commented not only upon the utility of the web page, but also upon the help they received in this unit of the library. Suggestions for items that they would like to see changed or added were few. The redesign of the subject-related material was quite popular. Overall there were few suggestions and much approval expressed for the redesign.

\section{Conclusions}

The redesign of the ESSL home page entailed a great deal of effort and no small expenditure of time and resources. In the end, it was felt to be well worth the work. The unit now has a page that is both easy to use and more attractive to users (Appendix F). In the process of redesigning the page, the team learned a great deal about users: their preferences, their concerns, and their knowledge of what is possible. Conclusions and lessons from this study include:

- Librarians should not assume users are aware of the resources available to them.

- The team concept works well in this type of situation. The differing views and talents of the team are as essential and beneficial as the results of the methodology employed.

- Focus groups are ideal for obtaining general information concerning the look and feel of web pages.

- Usability testing is essential to confirm the utility of the page.

- If a redesign is to be successful, it must have adequate support and funding.

- Do redesign during the middle of the academic year, when there are enough students on campus to develop large pools of candidates for testing, and plan to bring the page up during summer hiatus as opposed to the beginning of fall. This will provide more time to refine the page and assure its effective use, as well as provide an adequate pool of candidates from which to choose participants.

The final suggestions are to ask the right questions and to listen carefully to the answers. Repeated admonitions in the literature indicate that the results of discussions within focus groups tend to change from group to group. One meeting is definitely not adequate to the task. Take the results of these discussions and use professional judgment, derived either from the reference desk or other observation of user behavior, to assess what is really important and what is just a whim. As the web page is a continuing study in 
human-computer interaction, regularly ask users what they need and want through a variety of methods, as were conducted in this study. Information is a two-way street. Unless users are asked about their needs and expectations, it is impossible to adequately inform and provide access to the very population the library is charged with serving.

\section{References}

Allen, B. (1996). Information tasks: toward a user-centered approach to information systems. San Diego: Academic Press.

Allen, M., et al. (2001). Usability testing of interface design in the virtual library environment. National online $200122^{\text {nd }}$ New York: NY Online proceedings Information Today, 15-37.

Battleson, B., Booth, A., \& Weintrop, J. (2001). Usability testing of an academic library web site: A case study. Journal of Academic Librarianship, 27 (3):188-198.

Bawden, D. (1990). Evaluation of information systems and services. Aldershot: Gower.

Bickman, L. \& Rog, D. (Eds.) (1998). Handbook of applied social research methods. Thousand Oaks, Calif.: Sage Publications.

Cole, T. (1995). Mosaic on public-access PCs: Letting the World-Wide Web into the library. Computers-in-libraries, 15(1), 44-55.

Connaway, L. (1996). Focus group interviews: A data collection methodology for decision making. Library administration and management, 10(4), 231-39.

Dickstein, R., \& Mills, V. (2000). Usability testing at the University of Arizona Library: How to let the users in on the design. Information technology and libraries, 19(3), 146.

Edmunds, H. (1999). Focus group research handbook. Lincolnwood, IL: NTC Contemporary.

Faiks, A., \& Hyland, N. (2000). Gaining user insight: A case study illustrating the card sort technique. College \& research libraries, 61(4), 351.

Fern, E. (2001). Advanced focus group research. Thousand Oaks, CA: Sage Publications.

Glitz, B. (1997) The focus group technique in library research: An introduction. Bulletin of the medical library association, 85(4), 385-389.

Glitz, B. (1998). Focus groups for libraries and librarians. New York: Forbes.

Lindgaard, G. (1994). Usability testing and system evaluation: A guide for designing useful computer systems. New York:Chapman \& Hall.

Mayhew, D. (1999). The usability engineering lifecycle: A practitioner's handbook for user interface design. San Francisco, Calif.: Morgan Kaufmann Publishers.

McGillis, L., \& Toms, E. (2001). Usability of the academic library web site: Implications for design. College \& research libraries, 62(4), 355-67.

McMullen, S. (2001). Usability testing in a library web site redesign project. Reference services review, 29 (1): 7-22.

Mitchell, S., \& Atkinson, J. (2000). Sams teach yourself Active Server Pages 3.0 in 21 days. Indianapolis, IN: Sams.

Nielsen, J. (1994). Usability engineering. San Francisco, Calif.: Morgan Kaufmann Publishers.

Nielsen, J. (1997). The use and misuse of focus groups. IEEE software, 14(1), 94-95.

Nielsen, J. (2000). Designing web usability. Indianapolis, Ind.: New Riders.

Nielsen, J. (2000, March 19). Why you only need to test with five users. Alertbox March 19, 2000. Retrieved April 5, 2001 from, http://www.useit.com/alertbox/20000319.html

Nielsen, Jacob Ten Usability Heuristics. Heuristic Evaluation. Retrieved April 5, 2001, from, http://www.useit.com/papers/heuristic/heuristic_list.html

Norlin, E. \& Winter, CM! (2002). Usability testing for library web sites: a hands-on guide. Chicago: American Library Association. 
Inexact Science of Informing Ourselves

Rubin, J. (1994). Handbook of usability testing: how to plan, design, and conduct effective tests. New York: Wiley.

Schlichter, D. and Pemberton, J. (1992). The emperor's new clothes? Problems of the user survey as a planning tool in academic libraries. College \& research libraries, 53 (May).

Shneiderman, B. (1987). Designing the user interface: strategies for effective human--computer interaction. Reading, Mass.: Addison-Wesley.

Shneiderman, B. (1992). Designing the user interface: strategies for effective human--computer interaction (2nd ed.). Reading, Mass.: Addison-Wesley.

Shneiderman, B. (1998). Designing the user interface: strategies for effective human-computer-interaction (3rd ed.). Reading, Mass : Addison Wesley Longman.

Silverman, D. (2000). Doing qualitative research: a practical handbook._ Thousand Oaks, Calif.: Sage Publications.

Walbridge, S. (2000). Usability testing and libraries: The WSU experience. Alki, 16(3), 23-24.

Wood, L. (Ed.). (1998). User interface design: bridging the gap from user requirements to design. Boca Raton: CRC Press.

Young, V. (1993). Focus on focus groups. College and research libraries, 54(7), 291-394.

\section{Biographies}

Lynne Marie Rudasill is the Assistant Education and Social Science Librarian at the University of Illinois at Urbana-Champaign where she is the subject specialist in the areas of Political Science, Arms Control, and Sociology and works extensively in the area of library use instruction and training. A graduate of the University of Illinois, her publications have appeared in the New Review of Information Networking, the Serials Librarian, and the Proceedings of the International Association of Technical University Librarians.

Katherine McNeill-Harman is the Data Services Librarian at the Massachusetts Institute of Technology. Prior to this position she was a Graduate Reference Assistant at the University of Illinois Education and Social Science Library. In addition to the research conducted for the redesign of the Education and Social Science Library web page, she designed and conducted usability testing for the University of Illinois Library Gateway. Ms. McNeill-Harman holds a Master of Science in library and information science from the University of Illinois and a Bachelor of Arts in women's studies from Wesleyan University.

James R. Jacobs is a Graduate Student in Library and Information Science at the University of Illinois at Urbana-Champaign. He is a Reference Assistant at the Education and Social Science Library. His interests include computer-human interaction, library instruction, metadata and community access to public information. He is a founding member of the Urbana-Champaign Independent MediaCenter, and cocreator/Web designer for the U-C IMC Library of progressive resources.

\section{The authors wish to acknowledge the Research and Publication Committee of the University of Illinois at Urbana-Champaign Li- brary, which has provided support for the completion of the re- search reported in this paper.}




\section{Appendix A - Home Page as of 6/3/1998}

\section{WEC UNIVERSITY OF ILIINOIS AT URBANA-CHAMPIGN}

\section{Education and Social Science Library}

NEW

A new onine catalog will be here later this summer! After twenty years of using our current system, the Library will be switching to a completely new system on August 4. You can read more about the impending change by hooking into our informative Books \& Bytes web page.

- General Information (Address, hours, clickable map (149ki), steff, etc.)

- Ask-A-Lubrarian (Ask us a reference question)

- Searchable Online Databases: (UIUC access only) UIUC Online Catalog | WorldCat | ERIC | PsycINFO | Sociological Abstracts | Current Contents | Wilson Indezes | Electroric HRAF | Anthropological Index | Population Index | PAIS International | Linguistics \& Language Behavior Abstracts (LLBA) | Books-in-Print $\mid$ Social Sciences Citation Index (Web of Seinenee) | New Child Development Abstracts and Bibliography | Periodical Contents Indes (PCD) | More Databases

- Academic Disciplines:

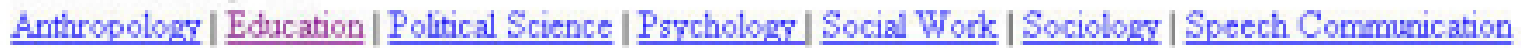

- General Collections: Print Joumals | Electroric Joumals | New Acquisitions Lists | Reserve Material

- Special Collections: Arms Control, Disarmament and International Security Collection | Curriculum Collection | School Collection | Tests Collection | Merten J. Mandeville Collection in the Occut Sciences

- Information Tools: Education and Social Science Library Research Guides | Print Statistical Sources | New Internet Statistical Sources | Social Sciences Citation Index | Human Relations Area Files | College Rankings | CD-ROM Databases I Online Catalog | Article Databases | Dipital Reference Collection

UIUC Main Library Home Page | UIUC Departmental Libraries | Interlibrary Loan | University of Ilnois at UrbanaChampaign $\mid$ Comments/Questions | Statement of Purpose

URL: http://wow libsary uiuc, edu/eds/ Last Updated $6 / 3 / 98$ deb

This HTML document was erested in the Edugation and Socis Science Library University of llinosis at Utbana-Chempaign 100 Main Lorary 1408 Wert Gregory Drive

Uabuna, II 61801

217-333-2305 


\section{Appendix B - Home page with Gateway access}

\begin{tabular}{|c|c|}
\hline Ed & $\begin{array}{l}\text { İon and Social Science Library } \\
\text { University of Ilinois at Urbana-Champaign }\end{array}$ \\
\hline $\begin{array}{l}\text { - Find Library } \\
\text { Materials } \\
\text { - Search for Articles } \\
\text { Use Reference Tools } \\
\text { - E Full Text } \\
\text { Learn About UIUC } \\
\text { Libraries/Services } \\
\text { Explore Digital } \\
\text { Projects } \\
\text { Read Hot Newa } \\
\text { Old UIUC Library } \\
\text { Home Page } \\
\text { Search } \\
\text { About This Menu }\end{array}$ & 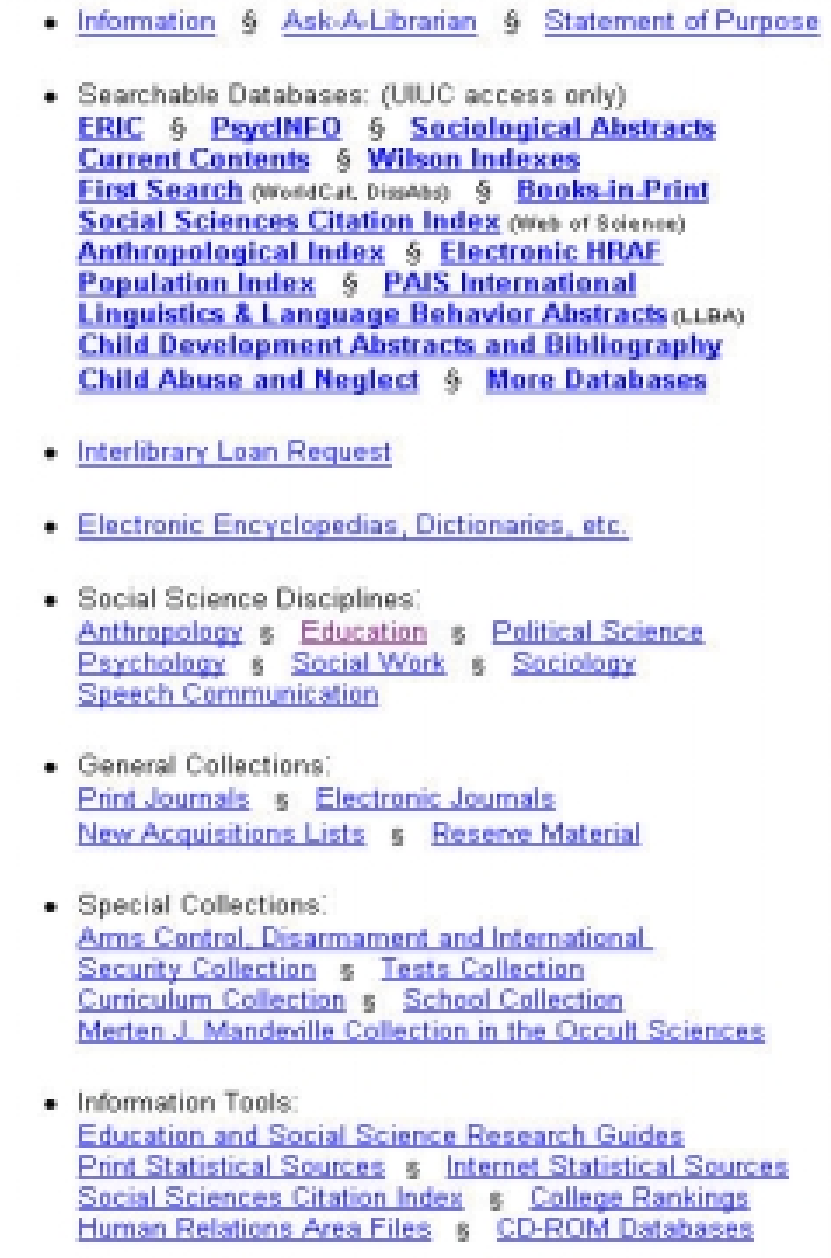 \\
\hline
\end{tabular}

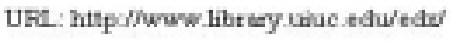

This HTMLL document was ceteated in the Eduetion and Bocial Beienee Library

University of Itlinois at Urbens-Champaign

100 Matn Library

1408 Weat Gregory Drive

Urbans, IL 61801

$217.333-2305$ 


\section{Appendix C - Enhanced home page}

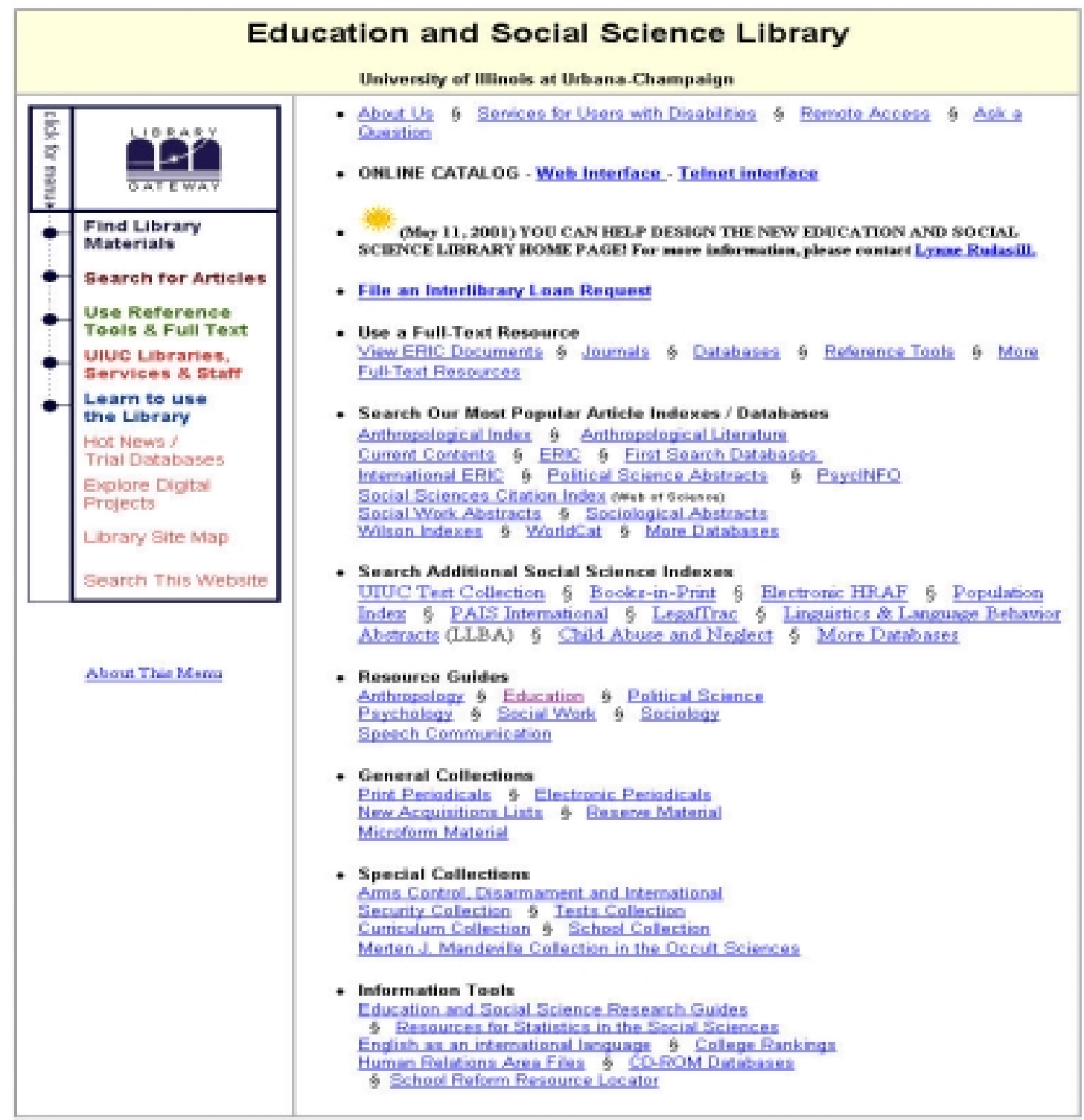

New 30,2001 , we

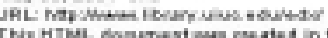
This

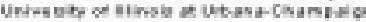
100 Man Linary

1400 wert shaery bere

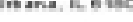

zir-axados 


\section{Appendix D - Prototype A}

\section{EDUCATION AND SOCIAL SCIENCE LIBRARY}

UNIVERSITY OF ILLINOIS AT URBANA-CHAMPAIGN

Welcome to the Education and Social Science Library Home page! To navigate this page use the pull-down menus to view all options in each area and click on the connect button to go to the page of your choice.

\begin{tabular}{|c|l|}
\hline & \\
\hline$\vdots$ & Find Library \\
$\vdots$ & Materials \\
$\vdots$ & Search for Articles \\
$\vdots$ & Use Reference \\
$\vdots$ & Tools \& Full Text \\
UIUC Libraries, \\
$\vdots$ \\
Services \& Staff \\
Learn to use \\
the Library \\
Hot News / \\
Trial Databases \\
Explore Digital \\
Projects \\
Library Site Map \\
Search This Website \\
\hline
\end{tabular}

Shortcuts to our most frequently used databases and library tools

CATALOGS

Find library materials on campus and beyond Anthropological Index

Go Illinet (web version)

\section{Go}

SUBJECT AREAS

Access resources that provide information on the desciplines we support

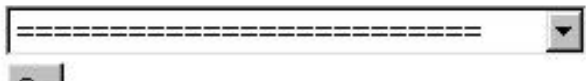

Go

\section{SPECIAL COLLECTIONS}

Unique resources associated with ESSL (including ACDIS, Mandeville, HRAF, and college rankings)

\section{Arms Control Collection}

Go

\section{ELECTRONIC RESOURCES}

Full-text materials including journals, databases, reference tools and more Go

LIBRARY SERVICES

Find hours, directory, email questions and more about ESSL
E-Journals About Us

About This Menu

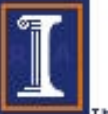

University of Illinois at Urbana-Champaign

Library Gateway Homepage

Comments/Questions

November 08,2000 jrj 


\section{Appendix E - Prototype B}

\section{EDUCATION AND SOCIAL SCIENCE LIBRARY}

UNIVERSITY OF ILLINOIS AT URBANA-CHAMPAIGN

Welcome to the Education / Social Science Library Home pagel There are two ways to navigate this page. 1) Click on the most popular links that have been designated in each section, or 2) Use the pull-down menus to view all options in each area and click on the connect button to go to the page of your choice.

\begin{tabular}{|l|l|}
\hline & \\
\hline & Gind Library \\
& Materials \\
\hline & Usearch for Articles \\
& Tools \& Full Text \\
Uiuc Libraries, \\
Services \& Staff \\
Learn to use \\
the Library \\
Hot News / \\
Trial Databases \\
Explore Digtal \\
Projects \\
Library Site Map \\
Search This Website \\
\hline
\end{tabular}

About This Merm
QUICK CONNECTIONS

EAIC I Yism EAIC Desumsents I Beychinte I Ses. Ssi. Citation Indear I Othet Autiole Databases

$==$
Go

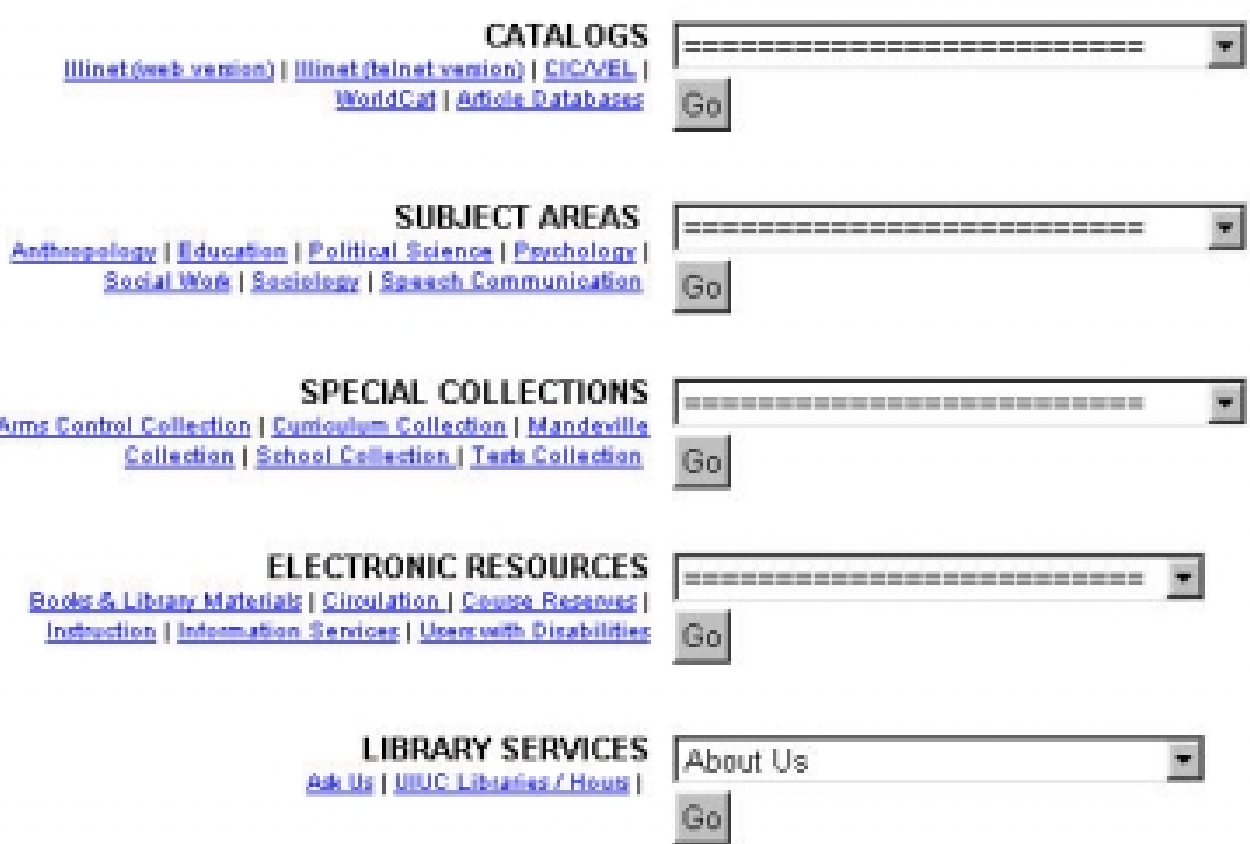

I Cellestion | Cumioulun Collection | Mandecille

ELECTRONIC RESOURCES

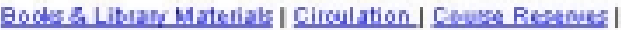

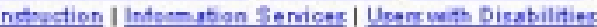

LIBRARY SERVICES

Aguas I UIUC Likatiss/ Heus |

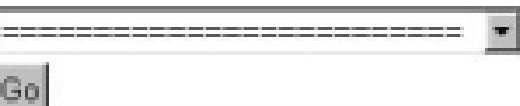

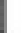

. 


\section{Appendix F - Current ESSL home page}

\section{EDUCATION AND SOCIAL SCIENCE LIBRARY}

\section{University of Illinois at Urbana-Champaign}

\begin{tabular}{|l|l|}
\hline & \\
\hline & LIBRARY \\
$\vdots$ & Materials \\
$\vdots$ & Search for Articles \\
$\vdots$ & Use Reference \\
\hline & Tools \& Full Text \\
& UIUc Libraries, \\
Services \& Staff \\
Learn to use \\
the Librany \\
Hot NewS / \\
Trial Databases \\
Explore Digital \\
Projects \\
Library Site Map \\
Search This Website \\
\hline
\end{tabular}

About This Menut

\begin{tabular}{|c|c|c|}
\hline \multicolumn{2}{|c|}{ :|: Choose a topic below for subject-oriented research :|: } \\
\hline Anthropology & Education & Political Science \\
\hline Psychology & Social Work & Sociology \\
\hline Hours & Speech Com. & About Us \\
\hline
\end{tabular}

Catalog Connections

Mlinet (web version) | Mlinet (telnet version) $\mid$ CIC/VEL (Biz10+ Libraries) $\mid$

Click Here To Browse More Options

WorldCat

Frequently Used Databases ERIC | View ERIC Documents | PsycINFO | Soc. Sci. Citation Index $\mid$ Article Databases

Electronic Resources Electronic Journals | Full-Text Databases

E-Reference | Trial Databases : Proquest

Click Here To Browse More Options

Services and Information Comments/Questions | E-Reserves | Email

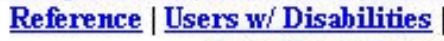
Click Here To Browse More Options Interlibrary Loan

Special Collections Arms Control Collection | Curriculum Collection | Mandeville Collection | Click Here To Browse More Options GO 